Jurnal Health Sains: p-ISSN: 2723-4339 e-ISSN: 2548-1398

Vol. 2, No. 8, Agustus 2021

\title{
PENGARUH BESARNYA ULTRAFILTRASI TERHADAP PERUBAHAN TEKANAN DARAH PADA PASIEN PGK DI UNIT HEMODIALISA RSUD KABUPATEN TANGERANG
}

\author{
Sulastri, Zahrah Maulidia Septimar, Lastri Mei Winarni \\ Sekolah Tinggi Ilmu Kesehatan (STIKes) Yatsi Tangerang, Banten, Jawa Barat, Indonesia \\ Email: astri@stikesyatsi.ac.id, tris2597@gmail.com, zahrahmaulidia85@gmail.com
}

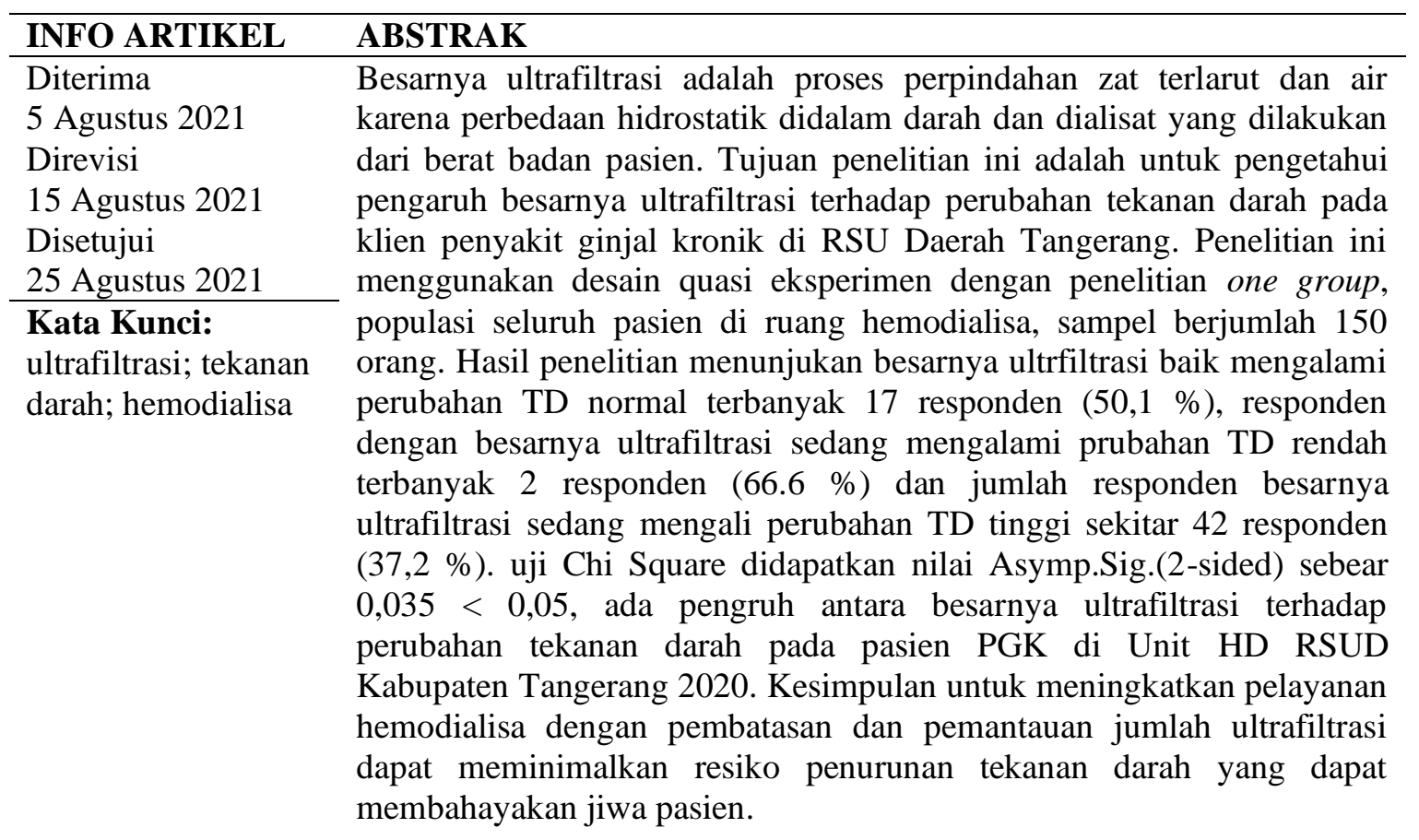

\section{ABSTRACT}

The magnitude of ultrafiltration is the process of transferring dissolved substances and water due to hydrostatic differences in blood and dialysate which are carried out from the patient's body weight. The purpose of this research is of the amount of ultrafiltration on changes in blood pressure in clients with chronic kidney disease at Tangerang Regional Hospital. Methods: This study used a quasi-experimental design with a one group study, the population of all patients in the hemodialysis room, a sample of 150 people. Results: The study showed that the amount of ultrfiltration both experienced changes in normal BP was 17 respondents (50.1\%), respondents with a moderate amount of ultrafiltration were experiencing a change in low BP, the most were 2 respondents $(66.6 \%)$ and the number of respondents, the amount of ultrafiltration, was multiplying changes in high BP, around 42 respondents. (37.2\%). Chi Square test obtained an Asymp.Sig. (2-sided) value of $0.035<0.05$, there is an influence between the amount of ultrafiltration on changes in blood pressure in CKD patients at the HD Keywords: $\quad$ Unit of the Tangerang District Hospital 2020. Conclusion to improve ultrafiltration; blood hemodialysis services with restrictions and Monitoring the amount of

$\begin{array}{ll}\text { How to cite: } & \text { Sulastri, S., Septimar, Z. M., \& Winarni, L. M. (2021) Pengaruh Besarnya Ultrafiltrasi terhadap } \\ & \text { Perubahan Tekanan Darah pada Pasien PGK di Unit Hemodialisa RSUD Kabupaten Tangerang. } \\ & \text { Jurnal Health Sains 2(8). https://doi.org/10.46799/jhs.v2i8.253 } \\ \text { E-ISSN: } & \text { 2723-6927 } \\ \text { Published by: } & \text { Ridwan Institute }\end{array}$




\begin{tabular}{ll}
\hline $\begin{array}{l}\text { pressure; } \\
\text { hemodialysis }\end{array}$ & $\begin{array}{l}\text { ultrafiltration can minimize the risk of a drop in blood pressure that can } \\
\text { endanger the patient's life. }\end{array}$ \\
\hline
\end{tabular}

\section{Pendahuluan}

Pembangunan kesehatan nasional diarahkan untuk meningkatkan kesadaran, kemauan hidup sehat bagi setiap warga agar peningkatan derajat kesehatan masyarakat yang setingi-tingginya dapat terwujud. Pembangunan kesehatan periode 2020-2024 adalah meningkatkan akses dan kualitas pelayanan kesehatan menuju cakupan kesehatan semesta dengan penekanan pada penguatan pelayanan kesehatan dasar (primary health care) dan peningkatan upaya promotif dan preventif didukung oleh inovasi dan pemanfaatan teknologi (Kemenkes, 2018).

Menurut data (Organization, 2018) bahwa sekitar 3.267.000 kematian tiap tahunnya disebabkan oleh penyakit ginjal dan saluran kemih, sehingga jumlah penyakit ini menunjukan dan menduduki peringkat ke-12 tertinggi angka kematian atau peringkat ke-17 angka kecacatan. Hasil Riset Kesehatan Dasar (Riskesdas, 2013) menunjukan prevalensi penyakit tidak menular mengalami kenaikan jika dibandingkan sedengan Riskesdas 2013 salah satunya adalah Gagal ginjal kronik naik dari $2 \%$ menjadi $3,8 \%$. Selain itu berdasarkan data jumlah penderita PGK di Indonesia menunjukan peningkatan berdasarkan sumber Indonesian Renal Regystry. Berdasarkan data IRR tahun 2017 jumlah pasien aktif sebesar 77.892 yang menjalani hemodialisa sedangkan 30.843 merupakan orang bary dan pasien yang melakukan hemodialisa (Oka et al., 2016).

Di Provinsi Banten angka kejadian penderita gagal ginjal kronis berdasarkan data Riset Kesehatan Dasar Provensi Banten (Riskesdas, 2013) menunjukkan jumlah Pravalensi penyakit ginjal kronik di Provinsi Banten sekitar 0,2 \% dari data Riskesda nasional. Sedangkan prevalensi tertinggi di Kabupaten Pandeglang sebesar 0,4 \%, diikuti oleh Kabupaten Serang 0,3 \%, Kabupaten Lebak dan kota Tangerang Selatan masingmasing sebesar 0,2 \%.Sementara Kabupaten Tangerang, Tangerang Kota dan Kota Serang masing-masing sebesar $0,1 \%$ (Kemenkes, 2018).

Jumlah pasien terminal gagal ginjal baru yang harus dilakukan HD berdasarkan data Riskesda Kabupaten Tangerang pada tahun 2017 adalah 1.873 orang dan meningkat pada tahun 2018 naik sebanyak 2.052 orang, sedangkan jumlah pasien yang menjalani hemodialisa di RSUD Kabupaten Tangerang dalam 3 bulan terakhir yaitu Mei. Juni dan juli sebanyak 513pasien.

Salah satu terapi yang dianjurkan untuk pengganti ginjal yaitu Hemodialisa, pengganti terafi ginjal ini disebut juga renal replacement therafy sehingga pasien yang melakukan HD sering mendapatlan gejala kelebihan volume cairan pasca HD. Hal ini terjadi karena dipicu adanya penurunan fungsi ginjal untuk mengekresikan cairan dalam tubuh (Wilson \& Prince, 1989).

Jika kelebihan cairan ini tidak terbuang maka dalam kurun waktu tertentu akan terjadi akumulasi penumpukan cairan ditubuh yang sangat berlebihan sehingga dapat terjadi oedema anasarka atau bahkan oedema paru yang akan dapat mengganggu pernafasan dengan resiko kematian. Pengeluaran atau pembuangan kelebihan cairan tubuh ini dapat dilakukan pada saat tindakan hemodialis dengan proses ultrafiltrasi. Dengan ultrafiltrasi maka kelebihan volume cairan akan dibuang, sehingga kelebihan cairan atau oedema ditubuh pasien akan berkurang (Wong \& Sarjana, 2017).

Cairan tubuh yang dibuang pada saat ultrafiltrasi adalah cairan intravaskuler, dengan berkurangnya jumlah cairan intravaskuler secara cepat pada saat proses hemodialisa maka volume pre load jantung 
juga akan turun sehingga pasien akan dapat mengalami penurunan tekanan darah atau hipotensi pada saat pelaksanaan hemodialisa (Tuyisenge, 2017). Sehingga penulis tertarik melakukan penelitian tentang "Pengaruh besarnya ultrafiltrasi terhadap perubahan tekanan darah pada pasien PGK di Unit Hemodialisa Rumah Sakit Umum Tangerang” (Black, 2008).

\section{Metode Penelitian}

Desain penelitian yang digunakan dalam penelitian ini adalah quasi eksperiment. Rencana penelitian yang akan digunakan yakni One Group yang melibatkan satu kelompok subjek (Gezginci et al., 2018).

Populasi dalam penelitian ini adalah pasien Hemodialisa yang melakukan HD di Rumah Sakit Umum Kabupaten Tangerang, sedangkan sampel dalam penelitian ini adalah total sampling sebanyak 150 responden sebagai pasien yang melakukan Hemodialisa di Ruang Hemodialisa RSUD Kabupaten Tangerang (Mbenu, 2019).

Alat pengumpulan data adalah lembar obeserrvasi responden dengan isi terkait besarnya ultrafiltrasi dan perubahan tekanan darah, dengan alat hemodialisa dan tekanan darah yang sudah dikalibrasi (Sudoyo et al., 2006).

Data yang didapatkan adalah batasan karateristi seperti umur, jenis kelamin dan lama hemodialisa. Dalam penelitian ini, analisa bivariat digunakan untuk menganalisa mendapatkan pengaruh besarnya ultrafiltrasi terhadap perubahan tekanan darah. Adapun teknik analisa data yang digunakan untuk menguji hipotesis adalah uji Wilcoxon dengan nilai diperoleh $\mathrm{p}$ value $(0,000)<\alpha$ $(0,05)$ maka ho ditolak (Hudak \& Gallo, 2013).

Hasil dan Pembahasan

\section{A. Hasil Penelitian}

Tabel 1

Distribusi Frekuensi Karakteristik Responden

\begin{tabular}{clcc}
\hline No & $\begin{array}{c}\text { Karakteristik } \\
\text { Responden }\end{array}$ & Frekuensi & \% \\
\hline $\mathbf{1}$ & Umur & & \\
\hline & Remaja & 3 & 25,3 \\
\hline & Dewasa & 38 & 72,7 \\
\hline \multirow{2}{*}{} & Lansia & 109 & \\
& Jenis & & \\
\hline & Kelamin & & 56 \\
\hline & Laki-laki & 84 & 44 \\
\hline \multirow{3}{*}{ Perempuan } & 66 & \\
\hline & Lama HD & & 17,3 \\
\hline
\end{tabular}

Dari hasil tabel 1 menunjukan bahwa umur responden yang melakukan hmodialisa di RSUD Tangerang 2020 sebagian besar lansia (>46 tahun) sebesar 109 responen $(72,7 \%)$, jenis kelamin responden laki-laki yang melakukan hemodialisa di RSUD Tangerang 2020 sebesar 84 responden (56\%), dan lama hemodialisa responden di RSUD Tangerang 2020 untuk kategori baru (3 tahun) sebanyak 124 responden $(82,7 \%)$ (Gustomi \& Rohmawati, 2016).

\section{Tabel 2}

\section{Pengaruh Besarnya Ultrafiltrasi Terhadap Perubahan Tekanan Darah Pada Pasien Penyakit Ginjal Kronik Di Unit Hemodialisa RSUD Kabupaten Tangerang 2020}

\begin{tabular}{|c|c|c|c|c|c|c|c|c|}
\hline \multirow{3}{*}{$\begin{array}{l}\text { Besarnya } \\
\text { Ultrafiltrasi }\end{array}$} & \multicolumn{6}{|c|}{ Tekanan Darah } & \multirow{3}{*}{$\begin{array}{l}\text { Total } \\
\mathbf{f}\end{array}$} & \multirow{3}{*}{$\begin{array}{c}\text { Asymptotic } \\
\text { Significance } \\
\text { (2-sided) }\end{array}$} \\
\hline & \multicolumn{2}{|c|}{ Normal } & \multicolumn{2}{|c|}{ Rendah } & \multicolumn{2}{|c|}{ Tinggi } & & \\
\hline & $\mathbf{f}$ & $\%$ & $\mathbf{f}$ & $\%$ & $\mathbf{f}$ & $\%$ & & \\
\hline Baik & 17 & 50,1 & 0 & 0 & 36 & 31,9 & 53 & 0.035 \\
\hline Sedang & 4 & 11,7 & 2 & 66,6 & 42 & 37,2 & 48 & \\
\hline Berat & 13 & 38,2 & 1 & 33,4 & 35 & 30,9 & 49 & \\
\hline Jumlah & 34 & 100 & 3 & 100 & 113 & 100 & 150 & \\
\hline
\end{tabular}


Berdasarkan tabel 2 jumlah responden dengan besarnya ultrfiltrasi baik mengalami perubahan tekanan darah normal terbanyak 17 responden $(50,1 \%)$, jumlah responden dengan besarnya ultrafiltrasi sedang mengalami prubahan tekanan darah rendah terbanyak 2 responden $(66.6 \%)$ dan jumlah responden besarnya ultrafiltrasi sedang mengali perubahan tekanan darah tinggi sekitar 42 responden (37,2\%) (Sukandar, 2006).

Berdasarkan uji Chi Square didapatkan nilai Asymp.Sig. (2-sided) pada uji Pearson Chi-Square adalah sebear 0,035. Karena nilai Asymp. Sig. (2sided) $0,035<0,05$, maka berdasarkan pengmbilan keputusan diatas, dapat disimpulkan bahwa HO ditolak dan $\mathrm{Ha}$ diterima. dengan demikian ada pengruh antara besarnya ultrafiltrasi terhadap perubahan tekanan darah pada pasien penyakit ginjal kronik di Unit Hemodialisa RSUD Kabupaten Tangerang 2020.

\section{B. Pembahasan}

1. Karakteristik Responden

a. Umur

Dari 150 responden yang melakukan hemodialisa di RSUD Tangerang sebagian besar adalah usia > dari 46 tahun (Lansia) yaitu sebanyak $72,7 \%$. Hal ini sesuai dengan pendapat (Pantara, 2016), bahwa faktor resiko yang berkaitan dengan terjadinya penyaikit gijal kronik antar lain adalah Umur. Hal ini diperkuat oleh pendapat Septimar Z.M, dengan judul faktorfaktor yag mempengaruhi hipotensi intraddialis pada pasien gagal ginjal kroniknyang menjalani HD. Hasil penelitian yang dilakukan di RSUD Tangerang dengan jumlah 63 responden didapatkan Sebagian besar responden berusia 46-65 tahun sebanyak 51 responden $(52,4 \%)$. Sama halnya dengan pendapat
Shofaniah yang berjudul perbedaan pengaturan ultrafiltrasi nonprofiling dengan ultrafiltrasi profiling satu terhadap penurunan tekanan darah Intradialisis Di Instalasi Hemodialisa RSUD Ulin Banjarmasin didapatkan sebagian besar responden berusia 46-55 tahun sebanyak 14 orang $(43,1 \%)$ dari 31 responden (Azizan \& Maryam, 2020).

b. Jenis Kelamin

Dari hasil penelitian menunjukan bahwa jenis kelamin responden yang melakukan hemodialisa di RSUD Tangerang adalah laki laki yaitu $56 \%$, ini menunjukan bahwa jenis kelamin laki laki lebih banyak dibanding perempuan yang hanya $44 \%$. Hasil penelitian ini berbeda dengan penelitian yang dilakukan oleh Septimar Z.M, Hasil penelitian yang dilakukan di RSUD Tangerang dengan jumlah 60 responden didapatkan Sebagian besar responden berjenis kelamin perempuan sebanyak 32 responden $(50,8 \%)$. Sedangkan penelitian menurut Shofaniah bahwa berdasarkan jenis kelamin yang melakukan hemodialisa yang terbnyak adalah laki-laki sebanyak 17 responden $(52,6 \%)$ dari 32 responden (Mansjoer et al., 2000).

Hal ini juga berbeda dengan hasil data Global Burden of Disease 2018 bahwa jenis kelamin perempuan rentan mengalami penyakit gagak ginjal kronik sehingga resiko terjadi kerusakan ginjal yang mengakibatkan dilakukannya Hemodialisa. Jenis kelamin perempuan lebih rentan karena karena mereka lebih rentan mengalami infeksi saluran kemih 
(ISK) dan preeklamsi yang dijumpai 3-10\% wanita hamil dan perempuan lebih rentan terkena penyakit sistemik lain seperti SLE, Rheumatoid Arthiritis (RA) dan Systemik Scleroderma (SS). Penyakit penyakit tersebut dapat meneyebabkan komplikasi berupa gagal ginjal kronik.

c. Lama Hemodialisa

Tingkat lamanya HD di RSUD Tangerang menunukan hasil dimana responden yang melaksanakan lamanya HD dengan kategori baru ( $<3$ tahun) sebesar 124 responden dan kategori lama (>4 tahun) sebesar 26 responden. Hal ini sesuai dengan penelitian oleh (Sufiana, 2016) tentang lama nya HD dengan kualitas hidup, bahwa HD merupakan terapi pengganti ginjal yang digunakan pasien dalam keadaan sakit akut dan pasien dengan penyakit ginjal stadium terminal. Seseorang yang telah divonis menderita gagal ginjal dan harus menjalani terapi pengganti ginjal seumur hidup pilihannya adalah HD (Sugiyono, 2008).

d. Pengaruh Pengaruh Besarnya Ultrafiltrasi Dengan Prubahan Tekanan Darah Pada Pasien Penyait Ginjal Kronik Di Unit Hemodialisa RSUD Tangerang 2020

Hasil Analisa
besarnya ultrafiltrasi $\begin{array}{r}\text { dengaruh } \\ \text { dengan }\end{array}$
perubahan tekanan darah pada
pasien penyait ginjal kronik Di Unit
Hemodialisa RSUD Tangerang
2020 bahwa terdapat 17 responden
$(50,1 \%)$ dari 34 responden
mempunyai besarnya ultrafiltrasi
baik dengan tekanan darah normal
dibanding dengan besarnya
ultrafiltrasi sedang dan berat yaitu 4

responden $(11,7 \%)$ dan 13 responden $(38,2 \%)$. Terdapat 2 $(66,6)$ responden dari 3 responden yang mempunyai besarnya ultrafiltrasi sedang dengan tekanan darah rendah dibanding dengan besarnya ultrafiltrasi baik dan berat dengan tekanan darah rendah yaitu $0 \%$ dan 1 responden $(33,4 \%)$. Sedangkan untuk besarnya ultrafiltrasi sedang dengan tekanan darah tinggi terdapat 42 responden $(37,2 \%)$ dari 113 responden dibandingkan dengan besarnya ultrafiltrasi baik dan berat dengan tekanan darah tinggi yatu sebesar 36 responden $(31,9 \%)$ dan 35 responden $(30,9 \%)$. Hasil penelitian ini diperkuat oleh Septimar ZM, bahwa karakteristik tekanan darah pre hemodialisa yang tidak mengalami hipotensi adalah sebanyak 45 responden $(71,4 \%)$, sedangkan tekanan darah pre hemodialisa yang mengalami hipotensi berjumlah 18 responden (28,6\%) (Maulidah, 2015).

Selain itu berdasarkan uji Chi Square didapatkan nilai Asymp.Sig. (2-sided) pada uji Pearson ChiSquare adalah sebear 0,035, maka ada pengaruh antara besarnya ultrafiltrasi terhadap perubahan tekanan darah pada pasien penyakit ginjal kronik di Unit Hemodialisa RSUD Kabupaten Tangerang 2020. Ini sejalan dengan penelitian (Nuriya et al., 2019), hasil penelitian menunjukan ada pengaruh antara laju ultrafiltrasi dengan tekanan darah pada pasien Hemodialisa di Ruang Hemodialisis Rumah Sakit Dr. H. Abdul Moeloek Provinsi Lampung. Selain itu penelitian yang dilakukan oleh (Shofaniah \& Suwandewi, 2018), 
bahwa terjadi penurunan tekanan darah intradialis karena adanya adanya perbedaan pegaturan ultrafiltrasi non-profiling dengan ultrafiltrasi profiling Di Instalasi Hemodialisa RSUD Ulin Banjarmasin (Adi Fanny, 2017).

\section{Kesimpulan}

Berdasarkan penelitian yang telah dilakukan mengenai pengaruh pengaruh besarnya ultrafiltrasi terhadap perubahan tekanan darah pada pasien penyakit ginjal kronik di Unit Hemodialisa RSUD Kabupaten Tangerang Tahun 2020, maka dapat disimpulkan distribusi frekuensi umur responden di unit Hemodialisa RSUD Tangerang 2020sebagian besar adalah Lansia (>46 tahun) sebanyak 109 responden $(72,7 \%)$ dari 150 responden.

Distribusi frekuensi jenis kelamin responden di unit Hemodialisa RSUD Tangerang 2020sebagian besar adalah berjenis kelamin laki laki sebanyak 84 responden $(56 \%)$ dari 150 responden.

Distribusi frekuensi besarnya laju ultrafiltrasi responden di unit Hemodialisa RSUD Tangerang 2020sebagian besar adalah baik sebanyak 53 responden $(35.3 \%)$ dibandingkan dengan besarnya laju ultrafiltrasi sedang (32\%) dan berat $(32,7 \%)$.

Distribusi frekuensi tekanan darah sebagian besar tinggi yaitu sebanyak 113 responden $(74,3 \%)$ disbandingkan dengan tekanan darah normal 22,7 \% dan tekanan darah rendah $2 \%$.

Ada pengaruh antara besarnya ultrafiltrasi terhadap perubahan tekanan darah pada pasien penyakit ginjal kronik di Unit Hemodialisa RSUD Kabupaten Tangerang Tahun 2020 dengan nilai $P$ value 0,035.219.

\section{BIBLIOGRAFI}

Adi Fanny, M. (2017). Studi Deskriptif Mengenai Character Strengths Pada Pasien Gagal Ginjal Kronis Di Rsai Bandung. Google Scholar

Azizan, N., \& Maryam, M. S. (2020). Analisis Biaya Dan Manfaat Berbagai Skema Untuk Pelayanan Hemodialisis Di Rumah Sakit Dr. Sitanala Tangerang. Jrb-Jurnal Riset Bisnis, 4(1), 39-48. Google Scholar

Black, J. M. (2008). Medical-Surgical Nursing. Clinical Management For Positive Outcomes. Volume I. Saunders. Google Scholar

Gezginci, E., Iyigun, E., Kibar, Y., \& Bedir, S. (2018). Three Distraction Methods For Pain Reduction During Cystoscopy: A Randomized Controlled Trial Evaluating The Effects On Pain, Anxiety, And Satisfaction. Journal of Endourology, 32(11), 1078-1084. Google Scholar

Gustomi, M. P., \& Rohmawati, D. Z. (2016). Pengetahuan Dengan Kecemasan Pada Pasien Terdiagnosis Gagal Ginjal Kronik (Knowledge With Anxiety In Patients With Chronic Renal Failure). Journals Of Ners Community, 7(1), 9296. Google Scholar

Hudak, C. M., \& Gallo, B. M. (2013). Keperawatan Kritis: Pendekatan Holistik (Critical Care Nursing: A Holistic Approach).(Edisi 5 Volume 1). Alih Bahasa Allenidekania, B., Susanto, Nerera, \& Yasmin. Jakarta: Egc. Google Scholar

Kemenkes, R. I. (2018). Hasil Utama Riskesdas 2018. In Online) Http://Www. Depkes. Go. Id/Resources/Download/InfoTerkini/Materi_Rakorpop_2018/Hasil\% 20riskesdas (Vol. 202018). Google Scholar 
Mansjoer, A., Triyanti, K., Savitri, R., Wardhani, W. I., \& Setiowulan, W. (2000). Kapita Selekta Kedokteran. Jakarta: Media Aesculapius, 86-92. Google Scholar

Maulidah, S. N. (2015). Studi Penggunaan Albumin Pada Pasien Penyakit Ginjal Kronik (Pgk)(Penelitian Di Instalasi Rawat Inap Ilmu Penyakit Dalam Rsud Dr. Soetomo Surabaya). Universitas Airlangga. Google Scholar

Mbenu, A. W. (2019). Asuhan Keperawatan Pada Klien Chronic Kidney Disease Dengan Masalah Hipervolemia Di Rumah Sakit Panti Waluya Sawahan Malang. Stikes Panti Waluya Malang. Google Scholar

Nuriya, M., Yoneyama, H., Takahashi, K., Leproux, P., Couderc, V., Yasui, M., \& Kano, H. (2019). Characterization Of Intra/Extracellular Water States Probed By Ultrabroadband Multiplex Coherent Anti-Stokes Raman Scattering (Cars) Spectroscopic Imaging. The Journal of Physical Chemistry A, 123(17), 39283934. Google Scholar

Oka, A., Suwitra, K., \& Soebadi, D. (2016). Obstructive Nephropathy Of Kidney Stone: The Role Of Caspase-3, Transforming Growth Factor-B And Tumor Necrosis Factor-A In Kidney Fibrosis. Bju International, 117. Google Scholar

Organization, W. H. (2018). Who Expert Consultation On Rabies: Third Report (Vol. 1012). World Health Organization. Google Scholar

Pantara, P. D. D. W. I. (2016). Hubungan Antara Kadar Ureum Dengan Kadar Hemoglobin Pada Pasien Gagal Ginjal Kronik. Universitas Muhammadiyah Purwokerto. Google Scholar

Riskesdas. (2013). Riskesdas 2013. In Jakarta Kementeri Kesehat Ri (Vol. 6). Google Scholar

Jurnal Health Sains, Vol 2, No 8, Agustus 2021
Shofaniah, S., \& Suwandewi, A. (2018). Perbedaan Pengaturan Ultrafiltrasi NonProfiling Dengan Ultrafiltrasi Profiling Satu Terhadap Penurunan Tekanan Darah Intradialisis Di Instalasi Hemodialisa Rsud Ulin Banjarmasin. Dinamika Kesehatan: Jurnal Kebidanan Dan Keperawatan, 9(2), 534-546. Google Scholar

Sudoyo, A. W., Setiyohadi, B., Alwi, I., Simadibrata, M., \& Setiati, S. (2006). Ilmu Penyakit Dalam Jilid Ii Edisi Iv. Jakarta: Departemen Ilmu Penyakit Dalam Fakultas Kesehatan Universitas Indonesia. Google Scholar

Sufiana, F. N. (2016). Analisis Perkembangan Perkebunan Kopi Di Provinsi Kalimantan Timur. Jurnal Ilmu Ekonomi Mulawarman (Jiem), 1(3). Google Scholar

Sugiyono. (2008). Metode Penelitian Pendidikan:(Pendekatan Kuantitatif, Kualitatif Dan $R \quad \& \quad D$ ). Alfabeta. Google Scholar

Sukandar, E. (2006). Gagal Ginjal Dan Panduan Terapi Dialisis. Bandung: $F k$ Unpad. Google Scholar

Tuyisenge, M. J. (2017). Exploration Of Factors Influencing Nurses' Performance In The Care Of Hemodialysis Patients At Selected Nephrology Units In Rwanda. University Of Rwanda. Google Scholar

Wilson, D. A., \& Prince, J. R. (1989). John Caffey Award. Mr Imaging Determination Of The Location Of The Normal Conus Medullaris Throughout Childhood. American Journal Of Roentgenology, 152(5), 1029-1032. Google Scholar

Wong, O. A., \& Sarjana, D. (2017). Analisis Perubahan Hemoglobin Pada Pasien Gangguan Ginjal Kronik (Ggk) Yang Menjalani Hemodialisa Selama 3 Bulan Di Rumah Sakit Perguruan Tinggi Negeri (Rsptn) Universitas Hasannudin 
Sulastri, Zahrah Maulidia Septimar, Lastri Mei Winarni

(Unhas) Makassar [Skripsi]. Makasar:

Skripsi Fk Universitas Hasanuddin

Makasar, 1-83. Google Scholar

Copyright holder:

Sulastri, Zahrah Maulidia Septimar, Lastri Mei Winarni (2021)

First publication right:

Jurnal Health Sains

This article is licensed under:

(c) $($ i) (2) 